\title{
The consequences of ageing, progeroid syndromes and cellular senescence on mechanotransduction and the nucleus
}

\author{
Document Version \\ Accepted author manuscript
}

Link to publication record in Manchester Research Explorer

Citation for published version (APA):

Gilbert, H., \& Swift, J. (2019). The consequences of ageing, progeroid syndromes and cellular senescence on mechanotransduction and the nucleus. Experimental Cell Research.

\section{Published in:}

Experimental Cell Research

\section{Citing this paper}

Please note that where the full-text provided on Manchester Research Explorer is the Author Accepted Manuscript or Proof version this may differ from the final Published version. If citing, it is advised that you check and use the publisher's definitive version.

\section{General rights}

Copyright and moral rights for the publications made accessible in the Research Explorer are retained by the authors and/or other copyright owners and it is a condition of accessing publications that users recognise and abide by the legal requirements associated with these rights.

\section{Takedown policy}

If you believe that this document breaches copyright please refer to the University of Manchester's Takedown Procedures [http://man.ac.uk/04Y6Bo] or contact uml.scholarlycommunications@manchester.ac.uk providing relevant details, so we can investigate your claim.

\section{OPEN ACCESS}




\section{Author's Accepted Manuscript}

The consequences of ageing, progeroid syndromes and cellular senescence on mechanotransduction and the nucleus

Hamish T.J. Gilbert, Joe Swift

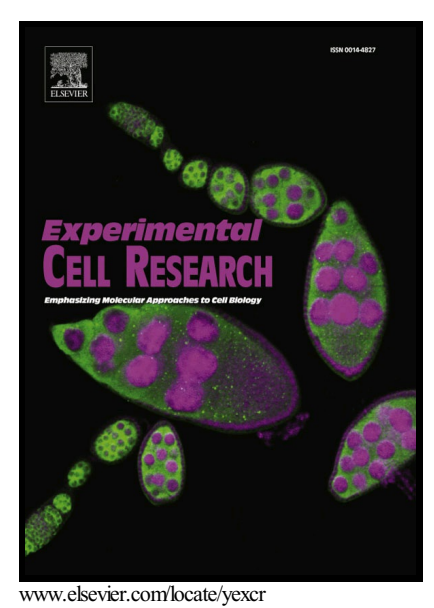

PII: $\quad$ S0014-4827(18)31025-5

DOI: $\quad$ https://doi.org/10.1016/j.yexcr.2019.03.002

Reference: YEXCR11338

To appear in: Experimental Cell Research

Received date: 27 September 2018

Revised date: 13 February 2019

Accepted date: 2 March 2019

Cite this article as: Hamish T.J. Gilbert and Joe Swift, The consequences of ageing, progeroid syndromes and cellular senescence on mechanotransduction and the nucleus, Experimental Cell Research, https://doi.org/10.1016/j.yexcr.2019.03.002

This is a PDF file of an unedited manuscript that has been accepted for publication. As a service to our customers we are providing this early version of the manuscript. The manuscript will undergo copyediting, typesetting, and review of the resulting galley proof before it is published in its final citable form. Please note that during the production process errors may be discovered which could affect the content, and all legal disclaimers that apply to the journal pertain. 
The consequences of ageing, progeroid syndromes and cellular senescence on mechanotransduction and the nucleus

Hamish T. J. Gilbert, Joe Swift

Wellcome Centre for Cell-Matrix Research, Division of Cell Matrix Biology and Regenerative Medicine, School of Biological Sciences, Faculty of Biology, Medicine and Health, Manchester Academic Health Science Centre, University of Manchester, Manchester, M13 9PL, UK.

hamish.gilbert@manchester.ac.uk

joe.swift@manchester.ac.uk

\section{ABSTRACT}

The ageing process is a progressive decrease in physiological function, caused by accruement of damage and misregulation in the cells and tissues of an organism. Human ageing has been the focus of much scientific investigation, but studies have been complicated by the variability of the process between subjects and the slow pace at which it occurs. Although the consequences of ageing on cellular biochemical signalling and metabolism have been well studied, the impact on the mechanical properties of cells and the extracellular matrix - and the mechanotransduction pathways that connect the two - have often been overlooked. In 


\section{ACCEPTED MANUSCRIPT}

this review we will discuss recent advances in the fields of nuclear and cytoskeletal biophysics, and consider this work in the context of ageing. In particular, we will examine the role of the nucleus in cellular mechanotransduction and in 'age-related diseases/phenomena' such as progeria and cellular senescence. Finally, we will discuss the therapeutic options being explored, drawing attention to a new field of medicine termed 'mechano-medicine' that may prove useful in addressing age-related pathology.

\section{KEYWORDS}

ageing, extracellular matrix (ECM), mechanotransduction, progeroid syndromes, senescence 


\section{ACCEPTED MANUSCRIPT}

\section{MAIN TEXT}

\section{Introduction}

The concept that increasing entropy indicates the direction of the "arrow of time" was suggested by the astronomer Arthur Eddington, and similarities may be drawn to the passage of time and the inexorable progression of ageing in human physiology. The ageing process causes loss of organisation, misregulation and accumulation of damage in cells and tissues. Within cells it can manifest in both loss of function, such as in senescence (cessation of cell division), or uncontrolled propagation, such as in cancer. Tissues are affected at microscopic and macroscopic levels, with altered composition and increased crosslinking in the extracellular matrix (ECM) causing stiffening and a loss of mechanical robustness [1]. Accrual of damage can eventually lead to tissue failure, and as such age is the greatest risk factor for many debilitating diseases and ultimately death. Scientific and medical communities have maintained a long interest in the study of ageing, perhaps from a desire to understand the limits of our mortality, but driven recently by a societal demand to maintain quality of life in an ageing global population. Nonetheless, ageing remains difficult to study: there are few reliable biomarkers for age, and the progression of ageing, influenced by both genetics and environmental conditions aggregated throughout life, varies greatly between individuals. The process of human ageing is also slow - certainly when compared to the duration of most research grants - and so furthering our understanding may require the identification of 


\section{ACCEPTED MANUSCRIPT}

tractable model systems, or the support for statistically robust longitudinal studies in human populations [2]

Ageing affects many aspects of cell biology. These have been systematically catalogued as 'hallmarks of ageing' [3]: genomic stability, telomere attrition, epigenetic alterations, loss of proteostasis, deregulation of nutrient sensing, mitochondrial dysfunction, cellular senescence, stem cell exhaustion, and altered communication between cells. Many of these processes, such as the maintenance of genomic stability and telomeres, suggest the importance of the nucleus in ageing. In addition, and although not explicitly mentioned amongst the hallmarks of ageing, the mechanical properties of many tissues are affected by ageing. This phenomenon has been characterised in organs such as skin and cardiovascular tissue, where the correct mechanical properties are essential for maintenance of function [1]. The relationship between cells and their surrounding environments is clearly important in defining the progression of ageing. However, there is limited understanding of the extent to which ageing tissue phenotypes are caused by failures of intracellular regulation propagating to the ECM, or whether accumulated 'wear-and-tear' on the ECM eventually affects the behaviours of tissue-resident cells.

In this review, we will examine the process of mechanotransduction - the conversion of mechanical signals from the ECM into biochemical signalling pathways - and how these 


\section{ACCEPTED MANUSCRIPT}

signals are propagated to the nucleus, where changes to nuclear proteins can impact mechanical integrity and function. We will discuss how changes to the intracellular proteome, in particular components of the nucleoskeleton and cytoskeleton, can influence the regulation of surrounding tissue. These processes will be considered in the context of physiological ageing, and also in progeroid syndromes and cellular senescence, both of which replicate some of the features of ageing. Finally, we will discuss the role of mechanical aspects in the design of therapeutic strategies against age-related pathologies.

\section{Ageing, the extracellular matrix and tissue mechanics}

The mechanical properties of tissues are aligned with their function, and as such, loadbearing tissues are stiff, and tissues with little requirement for robustness are soft [4, 5]. The mechanical properties of tissues are defined primarily by the ECM: this includes factors such as the concentrations and identities of ECM proteins (such as collagens and proteoglycans), along with their organisation and post-translational modification states (such as covalentlybonded crosslinks that stiffen tissues by tethering ECM molecules together). Healthy tissue integrity is maintained by homeostatic processes, whereby the expression of new ECM protein by tissue-resident cells is balanced by the secretion of matrix-degrading enzymes, such as those from the matrix metalloproteinase (MMP) and disintegrin and metalloproteinase with thrombospondin motif (ADAMTS) families of proteins. Additional layers of regulation are provided by tissue inhibitors of metalloproteinases (TIMPs), and crosslinking enzymes such as 


\section{ACCEPTED MANUSCRIPT}

lysyl oxidases (LOX family) [6]. During ageing the homeostatic balance can be disrupted, and

this can lead to changes in ECM composition and mechanical properties. For example, expression levels of the basement membrane protein laminin are reduced in ageing and this, in conjunction with elevated MMP expression, leads to a thinning of the basement membrane [6]. In addition, changes to the crosslinking between matrix proteins has been linked to agerelated tissue stiffening. Elevated levels of collagen crosslinking have been partly attributed to a build-up of advanced glycation end-products (AGEs), which accumulate in the long-lived (i.e. long half-life) ECM molecules over time and form at a greater rate under oxidative stress. The accumulation of AGEs occurs due to an age-related reduction in the expression levels of glyoxalase enzymes, which are part of the somatic cell machinery tasked with clearing glycation products $[6,7]$.

Age is typically amongst the greatest risk factors for a number of diseases associated with changes to the regulation, composition and mechanical properties of the ECM. While ECM composition and chemistry determine tissue mechanical properties, the role that tissue mechanical properties play in ageing and age-related disease is underappreciated. Many organs can be affected by fibrosis [8], whereby a failure of homeostasis drives the deposition of excessive ECM protein following injury, resulting in a stiffer scar tissue [1,9]. Cancers occurring in solid tissues share some of the features of fibrosis, including misregulation of ECM composition and crosslinking, meaning that cancer cells often reside within aberrantly 


\section{ACCEPTED MANUSCRIPT}

stiff tumours [10]. The ECM can also in some cases be a predictor of cancer: breast tissue stiffness, related to collagen content and assessed by mammographic density, is the strongest correlating factor to sporadic (non-inherited) breast cancer risk, after age [11]. As such, understanding how tissue and ECM mechanics contribute to, and are affected by, ageing and disease remains a fundamental question in biology.

\section{Cellular responses to mechanical inputs from their surroundings}

The behaviour of cells within tissues is influenced by a combination of biochemical and physical signals from the cellular environment. The emerging field of mechanobiology considers the broad range of cellular features shown to be influenced by mechanical stimulation, including cellular morphology, motility, transcriptional and proteomic regulation, proliferation and lineage specification [9]. These behaviours are regulated by pathways that convert mechanical stimulation into biochemical signals, a process referred to as mechanotransduction. The stiffness or elasticity of the environment is a key mechanical input: cells can remodel their cytoskeletons and nucleoskeletons such that they stiffen in response to stiff surroundings $[4,12]$. Stiffness-defined hydrogels have also been demonstrated to direct the lineage of mesenchymal stem cells (MSCs) [13].

Time can be an influential factor in modulating the response to stimulation. For example, MSCs have been shown to maintain a persistent epigenetic 'memory' of the mechanical 


\section{ACCEPTED MANUSCRIPT}

microenvironment [14], while cross-talk between mechanical signalling and the circadian cycle

has been observed in mammary cells [15]. In examinations of longer timescales, the age of the ECM has been shown to affect cell behaviour. The capacity of MSCs from mice to selfrenew and form bone is diminished in aged animals, but these properties were corrected when old cells were cultured on young ECM [16].

Cells interrogate their physical environments by pulling on the surrounding ECM and 'feeling' the resistance to deformation [9]. These interactions are mediated by integrin proteins embedded in the cell membrane. Integrins can be activated by binding to ligands in the ECM, leading to recruitment of additional intracellular proteins and the formation of adhesion complexes [17]. These complexes contain mechano-sensitive proteins, including the actin-binding protein talin, which become allosterically altered by force [18], exposing previously inaccessible cryptic binding sites and activating intracellular signalling cascades. Physical stimulation at adhesion complexes is transduced into biochemical signals, such as through regulation of the small GTPase RhoA, affecting the assembly and activity of actin / myosin-II stress fibres that enable cells to apply contractile forces against the surrounding ECM [17]. Another example of mechanotransduction is the translocation of transcription factors (TFs), such as yes-associated protein (YAP) [19], serum response factor (SRF) [20] and retinoic acid receptor gamma (RARG) [4]. Here, mechanical control of TF location within the cell exerts regulation over processes such as gene expression and differentiation. It was 
recently shown that nuclear compression resulted in increased YAP transport to the nucleus through deformation-induced opening of the nuclear pores [21]. Importantly, the intrinsic rigidity of the YAP protein was shown to affect the rate at which protein entered the nucleus. The extent to which this mechanism applies to other transport mechanisms, and whether it could be modulated by the ageing process, remains to be investigated.

\section{Transmission of mechanical stimulation to the nucleus}

Acto-myosin filaments, which are attached to mature adhesion complexes (and by extension to the ECM), are tethered at their opposing ends to the nucleus. This has been suggested to create a continuous mechanical linkage between the ECM and the transcriptional 'control centre' of the cell, along which signals might be transmitted $[22,23]$. The nucleus is contained by the nuclear envelope, consisting of inner and outer phospholipid bilayer membranes that enclose a perinuclear space that is continuous with the endoplasmic reticulum. The mechanical interface between cell and nucleus is mediated by the linker of nucleoskeleton and cytoskeleton (LINC) complex. The LINC complex is made up of three main families of conserved proteins: (i) The nesprin family, that interact with the cytoskeleton, but are also tethered to the nuclear envelope and have Klarsicht, ANC-1, Syne Homology (KASH) domains positioned at the outer nuclear membrane. (ii) The SUN family, that have Sad1p, UNC-84 (SUN) domains that bind to the KASH domains of nesprins. SUN proteins, which form trimers, span the perinuclear space and have $\mathrm{N}$-terminal domains that extend through the 


\section{ACCEPTED MANUSCRIPT}

inner nuclear membrane into the nucleoplasm. (iii) The intermediate filament lamin proteins, that line the inside of the nuclear envelope and bind to the nucleoplasmic domains of SUN proteins $[22,24]$.

Mammalian cells contain two main kinds of lamin, A-type (lamins A and C, spliceforms of the $\angle M N A$ gene), and $\mathrm{B}$-type (lamins $\mathrm{B} 1$ and $\mathrm{B} 2$, encoded by $\angle M N B 1$ and $\angle M N B 2$ genes, respectively) [24]. The nuclear lamina is important in defining the viscoelastic properties of the nucleus, with stiffness scaling according to the concentration of lamin-A/C $[4,25]$. The nuclear lamina also forms a physical link to chromatin, particularly through association with genepoor heterochromatin regions, termed lamina-associated domains (LADs) [26]. Lamins, along with other inner nuclear membrane proteins, including emerin and lamina-associated polypeptides (LAPs), function to organise the chromatin through indirect binding of chromatin via the protein barrier to auto-integration factors (BAFs) [24]. The dynamics of chromatin domains within the nucleus have been shown to depend on the lamin-A content of cells [27]. The functional importance of a mechano-transmission pathway was demonstrated by work in which the activity of a mechano-responsive reporter gene, stimulated by force applied to the outside of a cell via a magnetic bead, was shown to require an intact LINC complex [23].

The roles of the nucleus and the nuclear lamina as component parts in mechano-transmission are not passive, as the structures are actively remodelled in response to force. Nuclei have 


\section{ACCEPTED MANUSCRIPT}

been shown to stiffen in response to deformation, with dependence on the LINC complex, the

nuclear lamina and emerin [28]. The composition of the nuclear lamina scales according to the stiffness of the tissues in which cells reside: stiffer tissues contain more collagen in the extracellular matrix, and have cells with more lamin-A/C and correspondingly stiffer nuclei [4].

Stiffer nuclei have been suggested to be more robust, thus affording increased protection to genetic material in tissues under mechanical load $[4,5]$. Adaption of the nuclear lamina to be commensurate with the stiffness of the environment has been shown in MSCs to occur within several days, with mechano-sensitive phosphorylation of lamin- $A, C$ occurring within minutes $[4,29]$. Furthermore, the composition of the nuclear lamina was found to influence the stiffness-directed differentiation of MSCs. Over-expression of lamin-A, thus stiffening the nuclei, caused amplification of osteogenic lineage, whereas nuclear softening induced by lamin-A,C knockdown favoured adipogenesis [4]. The response of MSCs to short periods of high intensity strain cycling was recently reported to 'decouple' the nucleus from the cytoskeleton through regulation of SUN2 protein in the LINC complex, suggesting another rapid protective mechanism against mechanical stress [30]. We are beginning to define the mechanisms of mechano-transmission from cytoskeleton to nucleus, but the consequences of ageing on this process remain to be investigated. Age-related biochemical changes to the nucleus and cytoskeleton are likely to significantly affect mechanotransduction and mechanotransmission to the nucleus. 


\section{ACCEPTED MANUSCRIPT}

\section{Nuclear deformation and DNA damage}

The nucleus is the largest and stiffest organelle and as such is an important mechanical component of the cell. As the nucleus may have to deform in order for the cell to pass through constrictive regions in the ECM, it can play a limiting role in cell migration. Cells with stiffer nuclei, controlled by having more A-type lamins relative to B-type, showed reduced propensity to traverse size-limited pores, whereas cells with reduced lamin-A/C were more susceptible to damage during deformation [31]. Furthermore, the nucleus has been shown to rupture as cells squeeze through restrictions, causing genomic material to spill out into the cytoplasm. Although cells were subsequently able to repair these ruptures using components of the endosomal sorting complexes required for transport-III (ESCRT-III) machinery [32, 33], repeated challenges to nuclear integrity lead to an accrual of DNA damage [5]. There are clearly important consequences of DNA damage on the likelihood of acquiring oncogenic mutations, but loss of genomic stability is also a key 'hallmark' of an ageing cell [3]. However, the extent to which mechanically-induced nuclear rupture could contribute to the genomic instability observed in ageing is not known.

\section{The nuclear lamina in progeroid syndromes and ageing}

Premature ageing or progeroid syndromes are rare genetic disorders that have physiological characteristics comparable to those found in normal ageing, such as skin frailty, susceptibility to cardiovascular disease and osteoporosis. There are two main groups of genes affected by 


\section{ACCEPTED MANUSCRIPT}

the mutations that cause progeroid syndromes: those encoding proteins involved with DNA repair, and those encoding proteins that maintain the integrity of the nuclear envelope [34]. Disorders in which there is a failure to correctly process lamin-A are a major contributor to the second group. In healthy cells, prelamin-A is farnesylated (a hydrophobic posttranslational modification) near the c-terminal, but this part of the protein is cleaved in a twostage process by enzyme ZMPSTE24 to give the mature form of lamin-A. In HutchinsonGilford progeria syndrome (HGPS), a silent point mutation to the $L M N A$ gene activates a cryptic splicing site, leading to a truncated, permanently farnesylated form of lamin-A called progerin $[34,35]$. Progerin is toxic to cells, causing disruption to the integrity of the nuclear envelope, affecting the mechanical properties to cause a 'blebbing' phenotype, and perturbing the organisation of chromatin [36, 37].

HGPS is an example of a 'laminopathy', a genetic disorder affecting the nuclear lamina, and is correspondingly a 'nuclear envelopathy' . In addition to progeroid syndromes, the clinical symptoms of these mutations include skeletal and cardiac muscular dystrophies and lipodystrophies. The majority of these disorders are caused by defects to the LMNA gene, where dozens of deleterious point mutations have been characterised. Conversely, mutations to B-type lamins are rarely observed, and it is considered that they would be lethal during early development. Laminopathies often manifest in the stiff tissues where lamin- $A, C$ levels have been shown to be highest [4], perhaps emphasising the importance of lamin in 


\section{ACCEPTED MANUSCRIPT}

maintaining the integrity of cells under mechanically stressful conditions, or its role in mechanotransduction pathways. Other affected genes include ZMPSTE24 that encodes the prelamin-processing enzyme, associated with progeroid-like syndromes, and EMD that encodes the lamina-associated protein emerin and is the principal factor in Emery-Dreifuss muscular dystrophy (EDMD). Interestingly, EDMD and dilated cardiomyopathy can both be caused by mutations to $E M D$, but also to nesprins, suggesting a role for the LINC complex in this disease mechanism [38].

Research into laminopathies has led to the development of treatment strategies for such syndromes [34], but the extent to which lamin mutations can offer a 'model' of the ageing process, or whether they simply recapitulate only some of the phenotypes, is still debated. A recent review [34] has highlighted where the characteristics of progeroid syndromes overlap with the 'hallmarks' of normal human ageing [3], including increased DNA damage, telomere dysfunction, epigenetic changes, and alterations to the nuclear lamina. Furthermore, levels of progerin have been found to increase with age in the cells of otherwise healthy human subjects [39] and more specifically in ageing vascular endothelial cells, where the tissue has a defined mechanical role [40]. The relationship between cells with accumulated lamin-A defects and ageing ECM, particularly in the context of maintained integrity to mechanical loading, offers an interesting avenue for future research. 


\section{ACCEPTED MANUSCRIPT}

\section{Models of ageing and cellular senescence}

The ageing process is difficult to study in humans because of its complexity, the length of the time scales involved and differences in how individuals age caused by local environments and distinctive genetic backgrounds. While statistically robust, large and longitudinal studies have permitted advances in gerontology, cellular and molecular processes remain challenging to examine [2]. A range of model organisms have been adopted to address these issues, including yeast, nematodes, flies and mice [41]. The nematode C. elegans is of particular relevance to this review as its well-characterised development and cellular biology have led to its use in studies of chromatin organisation, the nucleus, mechanobiology and ageing [42]. In general, laboratory animals are practical models because they have considerably shorter lifespans than humans, can have defined or modifiable genetic makeup, and can be kept in controlled, disease-free environments. A key success of using a diverse set of models has been to identify common ageing mechanisms, such as the widely conserved insulin / insulinlike growth factor (IGF) pathway. However, studies have also highlighted a diversity of ageing mechanisms and there is limited evidence that the most conserved mechanisms, or even the ones found in animals with the greatest phylogenetic similarity to humans, have the greatest relevance to understanding the human ageing process [41].

The phenomenon of cellular senescence has been used as an in vitro model of ageing that is particularly amenable to examining subcellular and molecular processes. It is defined as the 


\section{ACCEPTED MANUSCRIPT}

loss of replication in non-apoptotic, otherwise viable cells. Onset of senescence can be beneficial to developmental processes, tissue remodelling following injury, and as a safeguard against tumorigenesis [43]. However, the accumulation of senescent cells is also a central feature of organismal ageing [3]. In this context, the build-up of senescent cells can hinder the regenerative capacity of tissue and promote inflammation, contributing to disease processes [43]. Cells can become senescent due to an accumulation of cellular damage induced by replication or stress. Replicative-induced senescence occurs through activation of cell cycle suppression factors p53 and p21, due to telomere shortening in the absence of telomerase, and is the predominant type of senescence observed in vitro [44]. Stress-induced senescence can be caused by a variety of environmental and cellular stressors, including increased levels of reactive oxygen species (ROS), endoplasmic reticulum stress and oncogene activation, and again occurs through activation of cell cycle suppressors [43, 45]. Nesprin, lamin-A/C and actomyosin dependent mechanical regulation of telomere mobility and stability has recently been demonstrated, suggesting a connection between age-related, replicative-induced cellular senescence and mechanotransduction [46].

Corresponding to a popular format amongst commentaries on ageing, a number of characteristic 'hallmarks' of cellular senescence have been described [43]. These include changes to cell morphology, the composition of the cell membrane, and an accretion of dysfunctional mitochondria that contribute to high levels of ROS. Activation of the NF-kB 


\section{ACCEPTED MANUSCRIPT}

signalling pathway causes senescent cells to release various growth factors, cytokines and proteinases, termed the senescence-associated secretory phenotype (SASP) [47]. This potentially has important consequences for tissue mechanical properties, with remodelling resulting from a combination of immune system activation and the expression on ECMmodifying enzymes such as MMPs [43]. Senescent cells have also been shown to alter the expression of intracellular proteins, particularly those associated with the nuclear envelope: lamin-B1 levels were characteristically supressed [48]; levels of lamin-A, LEM domaincontaining protein 3 (LEMD3, also known as MAN1) and lamin B receptor (LBR) were reported to be decreased while SUN1 levels were increased [49]. Alterations to the LINC complex during senescence could impact on how force is transmitted to the nucleus, resulting in an aberrant cellular mechano-response. Furthermore, senescence-induced decreases in lamin-B1 have been shown to change chromatin regulation, with hypo-methylated chromatin regions at the nuclear periphery interacting with LADs and heterochromatin foci forming towards the centre of the nucleus (termed senescence-associated heterochromatic foci, SAHF) [37]. Altered spatial organisation of heterochromatin and loss of connectivity between chromatin and the nuclear lamina may compromise mechano-transmission and lead to alterations in mechanically-induced gene expression.

\section{Outlook on therapeutic strategies}




\section{ACCEPTED MANUSCRIPT}

Our understanding of the mechanobiology of ageing is incomplete, but this review has sought to highlight the importance of the ECM and the nucleus as two central - and reciprocally connected - components that influence the course of organismal ageing (Figure 1). In many tissues, the correct maintenance of mechanical properties is necessary for function. Furthermore, as age-related accumulation of cellular damage places a burden on intracellular stress response pathways [45], mechanical perturbations represent an additional mode of stress that may further burden the stress response machinery. An understanding of how cells respond to mechanical stress during ageing is therefore important, and may suggest new pathways to target in therapeutic strategies against age-related disorders.

Because ageing is a complex and varied process, it is difficult to target therapeutically. Clearance of senescent cells has been shown to have a rejuvenating effect, increasing the longevity of tissue functionality and lifespan in mice [50]. However, drugs that remove senescent cells, called 'senolytics', are often intrinsically toxic and difficult to target effectively against the senescent cells that contribute towards undesirable effects $[2,43]$. We should, in general, be wary of targeting fundamental cellular behaviours that tangentially contribute to age-related decline, such as the mechanisms that promote the onset of cellular senescence, as these may have important functional or protective roles in other contexts. It is also possible that the reversal of some ageing phenotypes cannot be achieved by drug-based 


\section{ACCEPTED MANUSCRIPT}

strategies, for example where adult ECM is correctly ordered and templated only during earlier stages of development.

It has been suggested that, rather than targeting the upstream causes of ageing, it may be more effectual to address downstream issues as they occur, potentially with more pragmatic tissue engineering strategies [2]. There has been some recent interest in repurposing drugs already approved for use against conditions such as diabetes and inflammation to address age-associated problems in metabolic and immune system processes [2]. Furthermore, following recent appreciation of the role that mechanics plays in tissue and cell ageing, a new type of therapy has been proposed: 'mechano-medicine' has arisen as a strategy to address diseases linked to tissue stiffening [51]. Future therapies may involve direct treatment of stiff tissues that revert them to their original mechanical properties, ideally inducing a disease-free phenotype; or intervening on the actions of ECM-modifying components of the SASP [43].

\section{Concluding remarks}

This review has considered the processes of physiological ageing and how some aspects can be replicated by diseases, such as progeroid syndromes, or in model systems, such as senescent cells. It has focused on the reciprocal relationship between cells and the ECM, and in particular on how mechano-sensitive pathways could be affected by ageing. The ECM is 


\section{ACCEPTED MANUSCRIPT}

definitive of the function and mechanical properties of tissues, and influences the behaviours of tissue-resident cells. Properties of the ECM, such as its stiffness, are also fundamentally affected by the ageing process, altering function and contributing to pathology. A recurring theme of this review has been that human ageing is challenging to study: it is difficult to define as a single process and its systematic nature means that it is difficult to model adequately. Nonetheless, the benefits of an improved understanding of ageing on our ability to maintain quality of life in an ageing demographic could be profound. The effectiveness of emerging therapeutic interventions in to ageing that target ECM and mechano-signalling pathways is still to be determined, but there is potential for such novel strategies to improve how we manage ageing and age-related disease.

\section{Acknowledgements}

We apologise where seminal works have been omitted for reasons of brevity. HTJG and JS were funded by a Biotechnology and Biological Sciences Research Council (BBSRC) David Phillips Fellowship (BB/L024551/1); both were supported by the Wellcome Centre for CellMatrix Research (WCCMR; 203128/Z/16/Z). The authors declare no competing interests. 


\section{ACCEPTED MANUSCRIPT}

\section{References}

[1] J.M. Phillip, I. Aifuwa, J. Walston, D. Wirtz, The mechanobiology of aging, Ann. Rev. Biomed. Eng. 17 (2015) 113-141.

[2] V. Mallikarjun, J. Swift, Therapeutic manipulation of ageing: repurposing old dogs and discovering new tricks, EBioMedicine 14 (2016) 24-31.

[3] C. Lopez-Otin, M.A. Blasco, L. Partridge, M. Serrano, G. Kroemer, The hallmarks of aging, Cell 153 (2013) 1194-1217.

[4] J. Swift, I.L. Ivanovska, A. Buxboim, T. Harada, P.C.D.P. Dingal, J. Pinter, J.D. Pajerowski, K.R. Spinler, J.-W. Shin, M. Tewari, F. Rehfeldt, D.W. Speicher, D.E. Discher, Nuclear lamin-A scales with tissue stiffness and enhances matrix-directed differentiation, Science 341 (2013) 1240104.

[5] D.E. Discher, L. Smith, S. Cho, M. Colasurdo, A.J. Garcia, S. Safran, Matrix mechanosensing: From scaling concepts in 'omics data to mechanisms in the nucleus, regeneration, and cancer, Ann. Rev. Biophys. 46 (2017) 295-315.

[6] C. Frantz, K.M. Stewart, V.M. Weaver, The extracellular matrix at a glance, J. Cell Sci. 123 (2010) 4195-4200.

[7] M.Z. Xue, N. Rabbani, P.J. Thornalley, Glyoxalase in ageing, Semin. Cell Dev. Biol. 22 (2011) 293-301.

[8] D.C. Rockey, P.D. Bell, J.A. Hill, Fibrosis - A common pathway to organ injury and failure, N. Eng. J. Med. 372 (2015) 1138-1149.

[9] J.D. Humphrey, E.R. Dufresne, M.A. Schwartz, Mechanotransduction and extracellular matrix homeostasis, Nat. Rev. Mol. Cell Biol. 15 (2014) 802-812.

[10] M.W. Pickup, J.K. Mouw, V.M. Weaver, The extracellular matrix modulates the hallmarks of cancer, EMBO Rep. 15 (2014) 1243-1253.

[11] J.C. McConnell, O.V. O'Connell, K. Brennan, L. Weiping, M. Howe, L. Joseph, D. Knight, R. O'Cualain, Y. Lim, A. Leek, R. Waddington, J. Rogan, S.M. Astley, A. Gandhi, C.C. 


\section{ACCEPTED MANUSCRIPT}

Kirwan, M.J. Sherratt, C.H. Streuli, Increased peri-ductal collagen micro-organization may contribute to raised mammographic density, Breast Cancer Res. 18 (2016) 17.

[12] J. Solon, I. Levental, K. Sengupta, P.C. Georges, P.A. Janmey, Fibroblast adaptation and stiffness matching to soft elastic substrates, Biophys. J. 93 (2007) 4453-4461.

[13] A.J. Engler, S. Sen, H.L. Sweeney, D.E. Discher, Matrix elasticity directs stem cell lineage specification, Cell 126 (2006) 677-689.

[14] C. Yang, M.W. Tibbitt, L. Basta, K.S. Anseth, Mechanical memory and dosing influence stem cell fate, Nat. Mater. 13 (2014) 645-652.

[15] N. Yang, J. Williams, V. Pekovic-Vaughan, P.B. Wang, S. Olabi, J. McConnell, N. Gossan, A. Hughes, J. Cheung, C.H. Streuli, Q.J. Meng, Cellular mechano-environment regulates the mammary circadian clock, Nat. Commun. 8 (2017) 13.

[16] Y. Sun, W.P. Li, Z.D. Lu, R. Chen, J. Ling, Q.T. Ran, R.L. Jilka, X.D. Chen, Rescuing replication and osteogenesis of aged mesenchymal stem cells by exposure to a young extracellular matrix, FASEB J. 25 (2011) 1474-1485.

[17] J.D. Humphries, N.R. Paul, M.J. Humphries, M.R. Morgan, Emerging properties of adhesion complexes: what are they and what do they do?, Trends Cell Biol. 25 (2015) 388-397.

[18] A. del Rio, R. Perez-Jimenez, R.C. Liu, P. Roca-Cusachs, J.M. Fernandez, M.P. Sheetz, Stretching single talin rod molecules activates vinculin binding, Science 323 (2009) 638-641.

[19] S. Dupont, L. Morsut, M. Aragona, E. Enzo, S. Giulitti, M. Cordenonsi, F. Zanconato, J. Le Digabel, M. Forcato, S. Bicciato, N. Elvassore, S. Piccolo, Role of YAP/TAZ in mechanotransduction, Nature 474 (2011) 179-U212.

[20] J.T. Connelly, J.E. Gautrot, B. Trappmann, D.W.M. Tan, G. Donati, W.T.S. Huck, F.M. Watt, Actin and serum response factor transduce physical cues from the microenvironment to regulate epidermal stem cell fate decisions, Nat. Cell Biol. 12 (2010) 711-U177. 


\section{ACCEPTED MANUSCRIPT}

A. Elosegui-Artola, I. Andreu, A.E.M. Beedle, A. Lezamiz, M. Uroz, A.J. Kosmalska, R. Oria, J.Z. Kechagia, P. Rico-Lastres, A.L. Le Roux, C.M. Shanahan, X. Trepat, D. Navajas, S. Garcia-Manyes, P. Roca-Cusachs, Force triggers YAP nuclear entry by regulating transport across nuclear pores, Cell 171 (2017) 1397-+.

[22] M.L. Lombardi, D.E. Jaalouk, C.M. Shanahan, B. Burke, K.J. Roux, J. Lammerding, The interaction between nesprins and SUN proteins at the nuclear envelope is critical for force transmission between the nucleus and cytoskeleton, J. Biol. Chem. 286 (2011) 26743-26753.

[23] A. Tajik, Y.J. Zhang, F.X. Wei, J. Sun, Q. Jia, W.W. Zhou, R. Singh, N. Khanna, A.S. Belmont, N. Wang, Transcription upregulation via force-induced direct stretching of chromatin, Nat. Mater. 15 (2016) 1287-1296.

[24] Y. Gruenbaum, R. Foisner, Lamins: nuclear intermediate filament proteins with fundamental functions in nuclear mechanics and genome regulation, Annu. Rev. Biochem. 84 (2015) 131-164.

[25] J. Lammerding, L.G. Fong, J.Y. Ji, K. Reue, C.L. Stewart, S.G. Young, R.T. Lee, Lamins A and C but not lamin B1 regulate nuclear mechanics, J. Biol. Chem. 281 (2006) 2576825780.

[26] L. Guelen, L. Pagie, E. Brasset, W. Meuleman, M.B. Faza, W. Talhout, B.H. Eussen, A. de Klein, L. Wessels, W. de Laat, B. van Steensel, Domain organization of human chromosomes revealed by mapping of nuclear lamina interactions, Nature 453 (2008) 948-U983.

[27] I. Bronshtein, E. Kepten, I. Kanter, S. Berezin, M. Lindner, A.B. Redwood, S. Mai, S. Gonzalo, R. Foisner, Y. Shav-Tal, Y. Garini, Loss of lamin A function increases chromatin dynamics in the nuclear interior, Nat. Commun. 6 (2015) 9.

[28] C. Guilluy, L.D. Osborne, L. Van Landeghem, L. Sharek, R. Superfine, R. Garcia-Mata, K. Burridge, Isolated nuclei adapt to force and reveal a mechanotransduction pathway in the nucleus, Nat. Cell Biol. 16 (2014) 376-381. 


\section{ACCEPTED MANUSCRIPT}

[29] A. Buxboim, J. Swift, J. Irianto, A. Athirasala, Y.-R.C. Kao, K.R. Spinler, P.C.D.P. Dingal, D.E. Discher, Matrix elasticity regulates lamin-A,C phosphorylation and turnover with feedback to actomyosin, Curr. Biol. 24 (2014) 1909-1917.

[30] H.T.J. Gilbert, V. Mallikarjun, O. Dobre, M.R. Jackson, R. Pedley, A.P. Gilmore, S.M. Richardson, J. Swift, Nuclear decoupling is part of a rapid protein-level cellular response to high-intensity mechanical loading, BioRxiv doi.org/10.1101/317404 (2018).

[31] T. Harada, J. Swift, J. Irianto, J.-W. Shin, K.R. Spinler, A. Athirasala, R. Diegmiller, P.C.D.P. Dingal, I.L. Ivanovska, D.E. Discher, Nuclear lamin stiffness is a barrier to 3D migration, but softness can limit survival., J. Cell Biol. 204 (2014) 669-682.

[32] C.M. Denais, R.M. Gilbert, P. Isermann, A.L. McGregor, M. te Lindert, B. Weigelin, P.M. Davidson, P. Friedl, K. Wolf, J. Lammerding, Nuclear envelope rupture and repair during cancer cell migration, Science 352 (2016) 353-358.

[33] M. Raab, M. Gentili, H. de Belly, H.R. Thiam, P. Vargas, A.J. Jimenez, F. Lautenschlaeger, R. Voituriez, A.M. Lennon-Dumenil, N. Manel, M. Piel, ESCRT III repairs nuclear envelope ruptures during cell migration to limit DNA damage and cell death, Science 352 (2016) 359-362.

[34] D. Carrero, C. Soria-Valles, C. Lopez-Otin, Hallmarks of progeroid syndromes: lessons from mice and reprogrammed cells, Dis. Models Mech. 9 (2016) 719-735.

[35] M. Eriksson, W.T. Brown, L.B. Gordon, M.W. Glynn, J. Singer, L. Scott, M.R. Erdos, C.M. Robbins, T.Y. Moses, P. Berglund, A. Dutra, E. Pak, S. Durkin, A.B. Csoka, M. Boehnke, T.W. Glover, F.S. Collins, Recurrent de novo point mutations in lamin A cause Hutchinson-Gilford progeria syndrome, Nature 423 (2003) 293-298.

[36] A.D. Stephens, P.Z. Liu, E.J. Banigan, L.M. Almassalha, V. Backman, S.A. Adam, R.D. Goldman, J.F. Marko, Chromatin histone modifications and rigidity affect nuclear morphology independent of lamins, Mol. Biol. Cell 29 (2018) 220-233. 


\section{ACCEPTED MANUSCRIPT}

[37] T. Chandra, P.A. Ewels, S. Schoenfelder, M. Furlan-Magaril, S.W. Wingett, K. Kirschner, J.Y. Thuret, S. Andrews, P. Fraser, W. Reik, Global reorganization of the nuclear landscape in senescent cells, Cell Rep. 10 (2015) 471-483.

[38] G.G. Gundersen, H.J. Worman, Nuclear positioning, Cell 152 (2013) 1376-1389.

[39] P. Scaffidi, T. Misteli, Lamin A-dependent nuclear defects in human aging, Science 312 (2006) 1059-1063.

[40] M. Olive, I. Harten, R. Mitchell, J.K. Beers, K. Djabali, K. Cao, M.R. Erdos, C. Blair, B. Funke, L. Smoot, M. Gerhard-Herman, J.T. Machan, R. Kutys, R. Virmani, F.S. Collins, T.N. Wight, E.G. Nabel, L.B. Gordon, Cardiovascular pathology in Hutchinson-Gilford progeria: Correlation with the vascular pathology of aging, Arterioscler. Thromb. Vasc. Biol. 30 (2010) 2301-U2636.

[41] A.A. Cohen, Aging across the tree of life: The importance of a comparative perspective for the use of animal models in aging, Biochim. Biophys. Acta, Mol. Basis Dis. 1864 (2018) 2680-2689.

[42] O. Cohen-Fix, P. Askjaer, Cell biology of the Caenorhabditis elegans nucleus, Genetics 205 (2017) 25-59.

[43] A. Hernandez-Segura, J. Nehme, M. Demaria, Hallmarks of cellular senescence, Trends Cell Biol. 28 (2018) 436-453.

[44] U. Herbig, W.A. Jobling, B.P.C. Chen, D.J. Chen, J.M. Sedivy, Telomere shortening triggers senescence of human cells through a pathway involving ATM, p53, and p21(CIP1), but not p16(INK4a), Mol. Cell 14 (2004) 501-513.

[45] O. Pluquet, A. Pourtier, C. Abbadie, The unfolded protein response and cellular senescence, Am. J. Physiol., Cell Physiol. 308 (2015) C415-C425.

[46] D.S. Jokhun, Y. Shang, G.V. Shivashankar, Actin dynamics couples extracellular signals to the mobility and molecular stability of telomeres, Biophys. J. 115 (2018) 1166-1179. 


\section{ACCEPTED MANUSCRIPT}

[47] A. Salminen, A. Kauppinen, K. Kaarniranta, Emerging role of NF-kappa B signaling in the induction of senescence-associated secretory phenotype (SASP), Cell. Signal. 24 (2012) 835-845.

[48] A. Freund, R.M. Laberge, M. Demaria, J. Campisi, Lamin B1 loss is a senescenceassociated biomarker, Mol. Biol. Cell 23 (2012) 2066-2075.

[49] C. Lenain, O. Gusyatiner, S. Douma, B. van den Broek, D.S. Peeper, Autophagymediated degradation of nuclear envelope proteins during oncogene-induced senescence, Carcinogenesis 36 (2015) 1263-1274.

[50] D.J. Baker, B.G. Childs, M. Durik, M.E. Wijers, C.J. Sieben, J. Zhong, R.A. Saltness, K.B. Jeganathan, G.C. Verzosa, A. Pezeshki, K. Khazaie, J.D. Miller, J.M. van Deursen, Naturally occurring p16(Ink4a)-positive cells shorten healthy lifespan, Nature 530 (2016) 184-+.

[51] M.C. Lampi, C.A. Reinhart-King, Targeting extracellular matrix stiffness to attenuate disease: From molecular mechanisms to clinical trials, Sci. Transl. Med. 10 (2018) 14. 


\section{ACCEPTED MANUSCRIPT}

Figure 1. Cross-section through a cell, showing components involved in mechanotransmission from the extracellular matrix to the nucleus, including the linker of nucleo- and cytoskeleton (LINC) complex. The opposing cartoon indicates changes in senescent cells and aged matrix that could affect mechanotransduction signalling in cells.

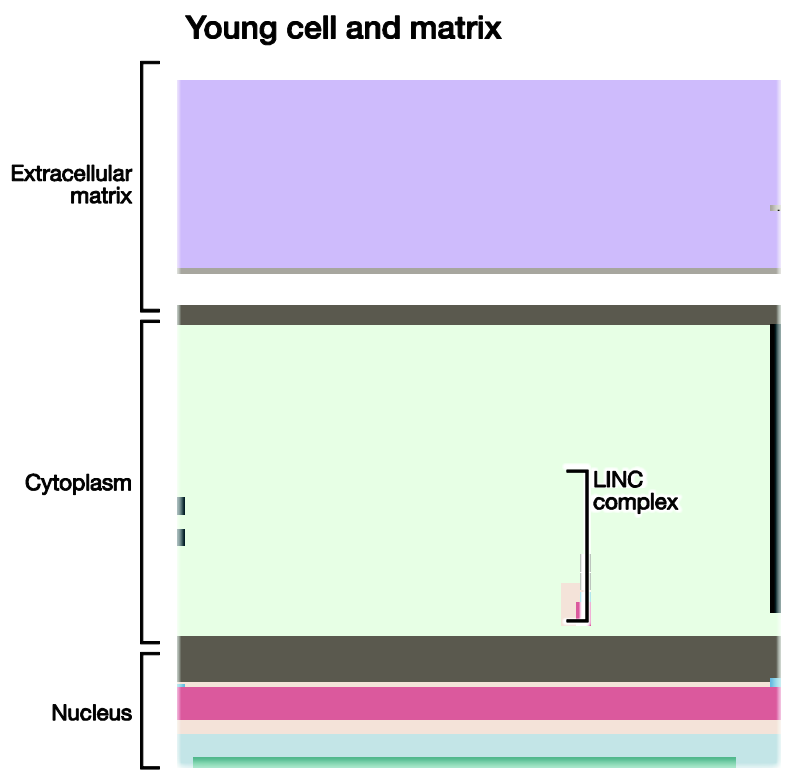

\section{Senescent cell \& aged matrix}

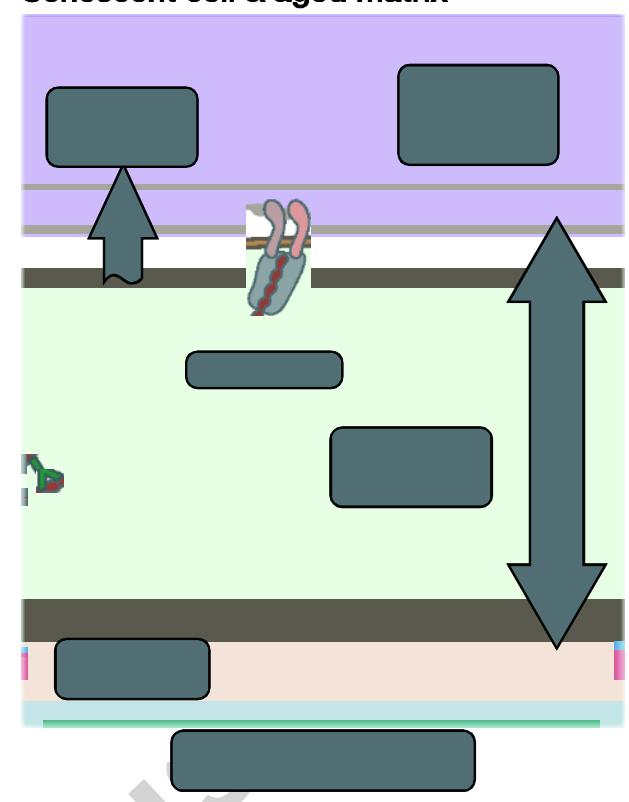

